\title{
Avaliação da agressividade na família e escola de ensino fundamental
}

\author{
Maria Cristina Rodrigues Azevedo Joly ${ }^{1}$ - Universidade São Francisco, Itatiba, Brasil \\ Anelise Silva Dias - Universidade São Francisco, Itatiba, Brasil \\ Janete Aparecida da Silva Marini - Universidade São Francisco, Itatiba, Brasil
}

\begin{abstract}
Resumo
O estudo objetivou identificar a percepção de crianças do ensino fundamental acerca da agressividade na família e escola, verificando possíveis diferenças entre essa variável com gênero, faixa etária, série e tipo de escola. Aplicouse uma escala de agressividade em 758 alunos brasileiros, de $2^{\mathrm{a}}$ a $4^{\mathrm{a}}$ séries, de ambos os sexos, sendo 50,4\% meninas. Os participantes apresentaram poucas condutas agressivas. A agressividade familiar teve maiores índices do que a escolar. Identificou-se influência do gênero sobre a agressividade geral dos participantes. Verificou-se que os meninos apresentaram índices de agressividade na família mais altos e significativamente diferentes em relação às meninas. Constataram-se diferenças significativas para idade e série apenas para agressividade familiar.

Palavras-chave: avaliação psicológica; agressividade familiar; agressividade escolar.
\end{abstract}

\section{Aggressiveness assessment in the family and fundamental school}

\begin{abstract}
The study aimed to identify the perception of children from the fundamental school between aggressiveness in the family and in the school, verifying possible differences among this variable with gender, age, grade and type of school. The aggressiveness scale was applied in 758 brazilian students, from second to fourth grade, of both genders, from which $50,4 \%$ were girls. The participants revealed few aggressive actions. The aggressive behavior in the family had higher level than the one in the school. The influence of gender on the aggressiveness of the participants was identified. Boys showed higher and more significant levels of agressivity in the family than girls. Significative differences for age and grade were ascertained only in family aggressiveness.

Keywords: psychological assessment; aggression in the family; aggression in the school.
\end{abstract}

\section{Considerações sobre agressividade}

A agressividade é uma das tendências de resolução de conflitos interpessoais muito estudada. No entanto, a agressão é uma conduta que, além de episódica, não é facilmente definível, assumindo diferentes formas de manifestação, cuja evolução está sujeita à influência de variáveis tanto biológicas quanto sociais (Leme, 2004). Para Buss (1961), a agressão é todo comportamento que fere ou traz prejuízo a outros. Skinner (1974) relaciona o comportamento agressivo a contingências de sobrevivência e reforço em função do ambiente. $\mathrm{Na}$ concepção de Bandura (1973), a agressão também pode consistir na condução de estímulos negativos de forte intensidade, provocando ferimentos físicos ou morais.

Segundo Bee (1997), Gomide (2000), Chaves, Kelder e Orpinas (2002), dentre outros pesquisadores, deve ser dada atenção à influência de determinadas condições ambientais que

\footnotetext{
${ }^{1}$ Endereço para correspondência:

Universidade São Francisco, Programa de Pós-graduação Stricto Sensu em Psicologia. Rua Alexandre Rodrigues Barbosa, 45, Centro, 13251-900, Itatiba-SP.

E-mail: cristinajoly@pq.cnpq.br
}

propiciam ou não o desenvolvimento do comportamento agressivo. A privação de alimento ou espaço físico, a retirada do afeto, dos cuidados parentais, a dor física ou psicológica, exposição frequente e/ou por longos períodos à agressividade, por meio de filmes e jogos interativos (videogame e de computador), são alguns exemplos que podem ser determinantes potenciais de altos índices de agressividade.

Outros aspectos que podem determinar o comportamento agressivo são as experiências pessoais, padrões e condições sociais da família (Davidoff, 2001). Estes podem constituir-se em risco à convivência, a princípio no núcleo familiar (Garcia \& Yunes, 2006) e, posteriormente, na escola e sociedade (Bronfenbrenner, 1996).

O comportamento agressivo exerce influência direta sobre o desenvolvimento pessoal e a vida em grupo. Os anos iniciais da vida de uma criança são de fundamental importância para o desenvolvimento de sua personalidade, relações sociais e adaptação social e psicológica durante o ciclo vital. Nas interações que as crianças estabelecem entre si, podem-se encontrar comportamentos positivos e negativos, como, por exemplo, agressão e altruísmo. Geralmente crianças de 2 e 3 anos de idade, quando se sentem tristes ou frustradas, apresentam comportamentos 
agressivos, como atirar objetos ou machucar-se. $\mathrm{Na}$ medida em que as crianças aperfeiçoam as habilidades verbais, modifica-se tal expressão, passando de agressões físicas a um maior uso da agressão verbal, o que ocorre na meninice intermediária, que vai até os 12 anos de idade (Bee, 1997; Lisboa \& Koller, 2001).

O comportamento agressivo expressa as dificuldades de interação e adaptação das crianças e adolescentes por meio de seus comportamentos. As crianças que apresentam condutas agressivas sabem que seus comportamentos são inadequados, porém têm dificuldades em considerar respostas não-agressivas para a resolução de seus problemas, como se as soluções possíveis se limitassem em luta ou fuga, sem alternativas entre os dois extremos (Leme, 2004). A agressividade infantil é identificada por meio do contato com o contexto sócio-histórico no qual a criança se desenvolve, considerando suas características de personalidade e desenvolvimento; além de poder ser apontada como fator de risco para o ajustamento familiar, social e escolar (Bronfenbrenner, 1996; Lisboa \& Koller, 2001).

As investigações de Leme (2004) exemplificam tais relações. Investigou, em dois estudos, aspectos envolvidos na violência interpessoal e algumas inter-relações entre cognição e afetividade no funcionamento psicológico. No primeiro estudo, a escala Children's Action Tendency Scale (CATS) foi aplicada em uma amostra de 779 alunos de $2^{\mathrm{a}}$ a $7^{\mathrm{a}}$ série. No segundo estudo foi usada a versão abreviada com uma amostra de 320 alunos de $5^{\mathrm{a}}$ a $7^{\mathrm{a}}$ série. No primeiro estudo, as tendências de resolução de conflito encontradas foram a assertividade, submissão e agressividade. Foram verificadas diferenças significativas nas médias de submissão e assertividade entre as duas amostras e diferenças entre os dois estudos nas tendências predominantes de resolução de conflitos, pois no segundo, submissão e agressividade sobrepujaram a assertividade, que ficou em último lugar.

Os ambientes nos quais as crianças vivem, como o contexto familiar e educacional, demonstram como a agressão pode influenciar o seu desenvolvimento psicológico. Algumas considerações sobre estes contextos fazem-se necessárias.

\section{Agressividade no contexto familiar e educacional}

Bolsoni-Silva e Marturano apresentaram uma revisão da literatura acerca de práticas parentais, contextos de aprendizagem e problemas de comportamentos, os quais foram assim definidos por serem agressivos ou hiperativos. Destaque será dado no presente estudo aos comportamentos agressivos que são indiretamente mais valorizados pela família e escola, constituindo-se, muitas vezes, como base dos relacionamentos. Em geral, surgem pela interação deficitária entre pais e filhos, no que se refere especialmente à comunicação e afeto, disciplina inconsistente, monitoramento e supervisão insuficientes das atividades infantis ou do adolescente.

O modelo de comportamento que os pais apresentam tem grande influência sobre o desenvolvimento da agressão na criança. A brutalidade na relação entre os pais e seus filhos, ensina às crianças, por meio da observação, o que fazer, assim, concluem que bater é apropriado e poderoso. A rejeição parental, a negligência, a disciplina rígida e a crueldade contra outros da família também estão ligadas à agressividade dos filhos (Bazi, 2003).

Bierman, Smoot e Aumiller (1993) realizaram pesquisa com 95 garotos divididos em 3 faixas etárias $(6-8 ; 8-10 ; 10-12)$. Os sujeitos foram selecionados com base sociométrica e avaliação da agressividade representando quatro grupos: (1) agressivo e rejeitado, (2) agressivo e não-rejeitado, (3) rejeitado e não-agressivo e (4) nem agressivo e nem rejeitado. Observações de comportamento, avaliação do professor, avaliação dos colegas e entrevistas com questionários foram utilizados como instrumentos para coletar informações que caracterizaram os comportamentos agressivos desses garotos nos domínios de conduta de sociabilidade e companheirismo, adaptabilidade e responsabilidade. Perfis problemáticos emergiram. Garotos agressivos-rejeitados apresentaram maior diversidade de condutas severas do que os meninos agressivos e não-rejeitados. O grupo nem agressivo nem rejeitado foi considerado pelos professores e colegas como deficientes em comportamentos pró-sociais e socialmente insensíveis.

No tocante ao contexto escolar, a agressividade pode ser decorrência da repetição dos padrões de relações familiares aprendidos ou mesmo da frustração e do próprio fracasso escolar. Ao lado disso, assim como os pais, os professores podem ser modelos inadequados para as crianças (Bolsoni-Silva \& Marturano, 2006; Polônia \& Dessen, 2005).

Ao ingressarem na educação infantil, crianças agressivas têm problemas de 
concentração, perceptivos e de aprendizagem. Suas dificuldades tendem a ser ignoradas nessa etapa inicial de escolaridade e, dessa forma, a criança vai para a escola fundamental sentindo-se incapaz de corresponder às expectativas. Frequentemente perdem o autocontrole, culpando os outros por seus problemas, comportando-se de maneira desafiadora e destrutiva. Os professores e diretores das escolas, em geral, tendem a considerá-los um transtorno e puni-los ou ridicularizá-los, gerando mais hostilidade e alienação (Papalia \& Olds, 2000).

Wagner e Biaggio (1996) identificaram a relação entre a forma como os pais lidam com sua agressividade e a maneira pela qual seus filhos préescolares se relacionam com os colegas. Participaram 80 crianças de ambos os sexos, com idade entre 3 e 5 anos, e seus pais. As crianças foram observadas por 90 minutos. Os pais foram avaliados pelo STAXI (State-trait anger expression inventory). Constatou-se que há uma correlação significativa e positiva entre os escores na subescala "raiva para fora" do STAXI de mães e o comportamento total de agressão. Houve um aumento dos comportamentos agressivos, tanto físicos quanto verbais, com o passar dos anos das crianças.

Para lidarem com o embaraço de repetidos fracassos, essas crianças elevam o nível de agressividade e destrutividade. Tendem a se juntar com outras crianças que têm histórico semelhante de fracasso e desprezo das autoridades e utilizam tais comportamentos para lidar com suas frustrações e sentimentos negativos. Desenvolvendo-se em ambientes cuja exposição à agressividade é contínua e por longo tempo, assumem padrões agressivos de interação como referência, tornam-se pouco tolerantes à frustração, demonstram baixa autoestima e falta de motivação para respeitar normas sociais (BolsoniSilva \& Marturano, 2006).

Tendo como referência da literatura a relação entre padrão familiar de agressividade, os relacionamentos interpessoais na escola e o desempenho acadêmico, Gardner, Powell e Grantham-McGregor (1998) analisam as relações entre aprendizagem e o comportamento de estudantes considerados agressivos comparadas às dos não-agressivos. Foram avaliados 102 garotos agressivos e 103 garotos não-agressivos de $5^{\text {a }}$ e $6^{a}$ séries selecionados pelos próprios colegas e por avaliações de seus professores. O grupo de alunos agressivos foi significativamente de crianças mais velhas $(M=11,4$ anos $)$ do que os não agressivos
$(M=11,1$ anos). Análises preliminares indicaram maior envolvimento em brigas dos garotos agressivos, quando comparados com o grupo nãoagressivo. Os garotos foram avaliados pelo Teste de Desempenho Escolar (WRAT) e Teste de Habilidade Verbal (Peabody Picture Vocabulary Test). Os pais dos garotos também foram avaliados quanto à agressividade. $\mathrm{O}$ grupo agressivo apresentou escores significativamente mais baixos na relação entre condição socioeconômica e desempenho acadêmico e vocabulário. O grupo agressivo relatou receber significativamente mais punições nos lares e relatou com maior frequência discussões e brigas entre os membros da família, tendo pais mais agressivos.

Visando identificar o efeito das estratégias de aprendizagem para diminuir as relações agressivas infantis que se manifestam no ambiente escolar, Loreto e cols. (1998) investigaram 12 alunos de $1^{\text {a }}$ série de ensino básico que apresentavam condutas agressivas. Os participantes frequentaram aulas extras com duração de seis semanas, nas quais aprenderam a usar estratégias de aprendizagem. Foram submetidos a pré e pós-teste para medir o aumento da efetividade do uso das técnicas e sua relação com o nível de agressividade. Verificou-se uma queda significativa do comportamento agressivo das crianças, mostrando ser positivo o ensino de estratégias de aprendizagem para tal fim.

Sisto e Fernandes (2004) analisaram a relação entre agressividade e dificuldades de aprendizagem na escrita. Participaram 834 alunos com idade de 8 a 12 anos, de escolas particulares e estaduais. Foram utilizados como instrumentos a Escala de Agressividade para Crianças e Jovens e a Avaliação das Dificuldades de Aprendizagem na Escrita (ADAPE). Os resultados apontaram que as dificuldades linguísticas $e$ as medidas de agressividade escolar apresentam grandes semelhanças nos resultados das segundas $\mathrm{e}$ terceiras séries. Observou-se que o aumento dos erros na escrita foi acompanhado do aumento das pontuações em agressividade escolar. Contudo, houve uma diferenciação estatisticamente significativa quanto ao gênero, em alunos de quarta série. As meninas apresentam coeficientes positivos e os meninos apresentam correlações negativas, quanto à dificuldade em escrita e agressividade.

Considerando que múltiplos fatores estão envolvidos na ocorrência de comportamentos agressivos, Chaves, Kelder e Orpinas (2002) realizaram um estudo com o objetivo de avaliar a 
diferença de agressividade entre 5.831 crianças do ensino fundamental de origem latina que frequentavam escolas públicas americanas. Foram divididas em dois grupos - as que jogavam videogame frequentemente e as que eram pouco expostas a essa atividade. Um relacionamento linear foi observado, entre o tempo gasto jogando e as pontuações de agressividade. Altos escores agressivos foram significativamente associados com jogos agressivos em meninos e meninas. A maioria dos estudantes que jogavam, "lutavam" na escola. Os estudantes latinos que estavam mais adaptados à língua e à cultura americana mostraram preferência por jogos mais violentos. Verificou-se, também, que os alunos que relataram falar mais espanhol em casa e com seus amigos, mostraram-se menos propensos a jogar videogame por muito tempo e revelaram ter menor preferência por jogos violentos.

Gomide (2000) avaliou a influência de filmes violentos em comportamento agressivo em crianças e adolescentes em dois experimentos, dos quais participaram 520 sujeitos de ambos os sexos. O comportamento agressivo foi medido por meio de observações após assistirem a filmes violentos e não-violentos. Os resultados apontaram que $O$ comportamento agressivo de crianças e adolescentes do sexo masculino aumentou após assistirem a um filme violento. $O$ mesmo não ocorreu com as crianças e adolescentes do sexo feminino. Contudo, quando a violência refletiu abusos físico, psicológico e sexual, houve um aumento significativo do comportamento agressivo em adolescentes de ambos os sexos.

Em síntese, nos estudos descritos na presente investigação e na análise da literatura feita por Bolsoni-Silva e Marturano (2006), a agressividade é um comportamento multideterminado. As variáveis características da pessoa, história de vida familiar, práticas parentais, condições socioeconômicas, eventos estressantes e contexto familiar podem influenciar o aparecimento e/ou manutenção de comportamentos agressivos.

Considerando-se que a criança ou adolescente, ao ser agressiva, pode ser rejeitada tanto pela família quanto pela escola e destacandose, dentre as variáveis elencadas, o contexto familiar e escolar, o presente estudo teve por objetivo identificar a percepção de estudantes do ensino fundamental acerca da agressividade na família e escola. Verificaram-se possíveis influências do gênero, idade e série frequentada pelos participantes sobre sua percepção.

\section{Método}

\section{Participantes}

O estudo foi desenvolvido em seis escolas da rede pública $(90,9 \%)$ e particular $(9,1 \%)$ de ensino, de três cidades do interior do estado de São Paulo. Participou uma população de 758 crianças de segunda série $(43,9 \%)$, terceira série $(29,2 \%)$ e quarta série $(26,9 \%)$. Os alunos eram de ambos os sexos, sendo $50,4 \%$ do feminino e 49,6\% do masculino, com idade variando de 7 a 13 anos, com uma média de 9,01 anos e desvio padrão de 0,96 .

\section{Instrumento}

Escala de Agressividade para Crianças e Jovens (Sisto \& Bazi, 1998)

Tem por objetivo fornecer três medidas de agressividade relativas à percepção de comportamentos agressivos em situação familiar, escolar e agressividade geral. É composta por dezesseis afirmativas, sendo oito referentes à situação familiar e outras oito referentes à situação escolar. Para cada afirmativa, os respondentes assinalaram a resposta sim ou não, em função da presença ou ausência do comportamento descrito no item. A cada resposta sim foi atribuído um ponto, e a resposta não foi desconsiderada. Dessa maneira, as subescalas de agressividade em situação familiar e escolar variam de 0 a 8 pontos cada uma; e a Escala de Agressividade Geral, varia de 0 a 16 pontos. Alguns exemplos dos itens da subescala para agressividade em situação familiar são: Bato nos meus irmãos para defender os meus direitos; Quando as pessoas da minha casa me xingam, sinto raiva; Gosto de ameaçar os meus irmãos. E, para a subescala de agressividade escolar são: Faço brincadeiras com as pessoas da minha escola que deixam elas chateadas; Machuco meus colegas da escola quando tenho vontade; Faço inimigos facilmente na escola.

A análise das características psicométricas do instrumento realizada por (Sisto \& Bazi, 1998) revelou a existência de dois fatores (agressividade em situação familiar e escolar) pela análise fatorial dos itens. O estudo de precisão realizado com o instrumento revelou que os coeficientes alfa são, para a subescala de agressividade em situação familiar, 0,76; para a subescala de agressividade em situação escolar, 0,71; e para a escala geral, 0,80.

\section{Procedimento}

Após a aprovação do projeto pelo Comitê de Ética, foi realizado contato com as direções das instituições de ensino solicitando autorização. 
Num segundo momento foi enviado aos pais/responsáveis pelos alunos Termo de Consentimento Livre e Esclarecido, solicitando autorização para a participação de seus filhos na pesquisa. Participaram do estudo os alunos que entregaram o termo de consentimento assinado pelos pais ou responsável.

A aplicação do instrumento foi realizada coletivamente nas classes, com no máximo quarenta crianças, em horário escolar, pela pesquisadora. Foram esclarecidas as instruções, iniciando-se a aplicação, onde cada afirmativa foi lida em voz alta pela aplicadora, fornecendo tempo para que os alunos respondessem cada item. O tempo médio de aplicação variou de 10 a 14 minutos.

\section{Resultados e discussão}

A análise descritiva dos dados revelou que o escore total de agressividade dos participantes foi de 4,17 pontos, em média, com desvio padrão de 2,86. De forma geral, os participantes apresentaram poucas condutas agressivas, uma vez que a média alcançada não atingiu o ponto médio da escala (8 pontos). Foram observadas duas concentrações de pontuações. A primeira entre 0 e 5 pontos, responsável por $73,4 \%$ das respostas, sendo essas pertencentes aos itens da subescala familiar; e a segunda, compreendendo o intervalo de 6 a 10, pontos indicando uma porcentagem de $24,4 \%$, referindo-se à subescala escolar.

Identificou-se influência do gênero sobre a agressividade geral dos participantes $[t(756)=-3,40$; $p<0,00]$, mas não houve diferenças significativas para tipo de escola frequentada pelos participantes $[t(756)=1,29 ; \quad p<0,19], \quad$ nem por série $[F(2,755)=12,46 ; p<0,22]$ e nem por idade $[F(4$, $755)=11,70 ; p<0,22]$. Esses dados corroboram o estudo de Sisto e Fernandes (2004).

Apesar de revelarem índices baixos, estes resultados confirmam evidências da literatura (Bolsoni-Silva \& Marturano, 2006; Polônia \& Dessen, 2005; Bronfenbrenner, 1996). As crianças cujos comportamentos agressivos são aprendidos em casa e se tornam padrões de interação, manifestam-se também na situação escolar.

\section{Agressividade em Família}

No que se refere especificamente à agressividade familiar, verificou-se uma média de 3,05 e um desvio padrão equivalente a 1,90. As pontuações concentraram-se fortemente entre 0 e 5 pontos, cujo percentual cumulativo foi de $90,4 \%$.
As maiores pontuações dessa escala deram-se nos itens 2 (quando as pessoas da minha casa me xingam, sinto raiva), 3 (ao discutir com alguém da minha familia, acabo brigando) e 4 (gosto de ameaçar os meus irmãos), explicando a conduta de 54,6\% dos participantes. Assim, pôde-se perceber que houve uma tendência dos sujeitos a apresentarem poucas condutas de agressividade na situação familiar, já que a concentração está abaixo do ponto médio da escala (4), que podia variar de 0 a 8 pontos.

Apesar das condutas agressivas na família serem pouco frequentes, o resultado da presente investigação corrobora os estudos de Lisboa e Koller (2001), Bazi (2003) e Leme (2004) quanto ao papel da família como determinante para o desenvolvimento de condutas sociais e a aprendizagem de comportamentos eficazes para a solução de conflitos. Ao lado dessa constatação, a frequência alta de respostas ao item 4 - gosto de ameaçar os meus irmãos, confirma a afirmação de Bolsoni-Silva e Marturano (2006) sobre os comportamentos coercitivos utilizados e valorizados pelos pais como meio para respeitar regras e normas sociais, que passam a ser utilizados amplamente pelos filhos. Vale destacar ainda, que no estudo de Gardner, Powell e Grantham-McGregor (1998) o grupo de participantes que apresentou maiores comportamentos agressivos relatou receber significativamente mais punições nos lares e participar com maior frequência de discussões e brigas entre os membros da família.

Considerando a agressividade familiar em relação à série e ao tipo de escola frequentada pelos participantes, pode-se identificar, na Figura 1 , que houve um aumento nos escores médios de agressividade à medida que os participantes avançam nas séries. Apenas na segunda série, a escola da rede pública de ensino obteve uma média superior à média dos alunos da rede particular. Nas demais séries, os índices apresentados foram superiores para a escola particular.

De acordo com Bronfenbrenner (1996), a expressão da agressividade depende do momento individual de cada indivíduo e, desse modo, o aumento da agressividade entre as séries pode estar relacionado à expressão e tentativa de controle das exigências crescentes quanto à aprendizagem por parte das crianças. Se houver uma baixa autoestima e falta de motivação para enfrentar desafios, elas acabam por perder o autocontrole, culpando os outros por seus problemas, comportando-se de maneira 
desafiadora e destrutiva, como reação padrão anterior, muito provavelmente já aprendida como forma de controlar situações adversas (Polônia \& Dessen, 2005).

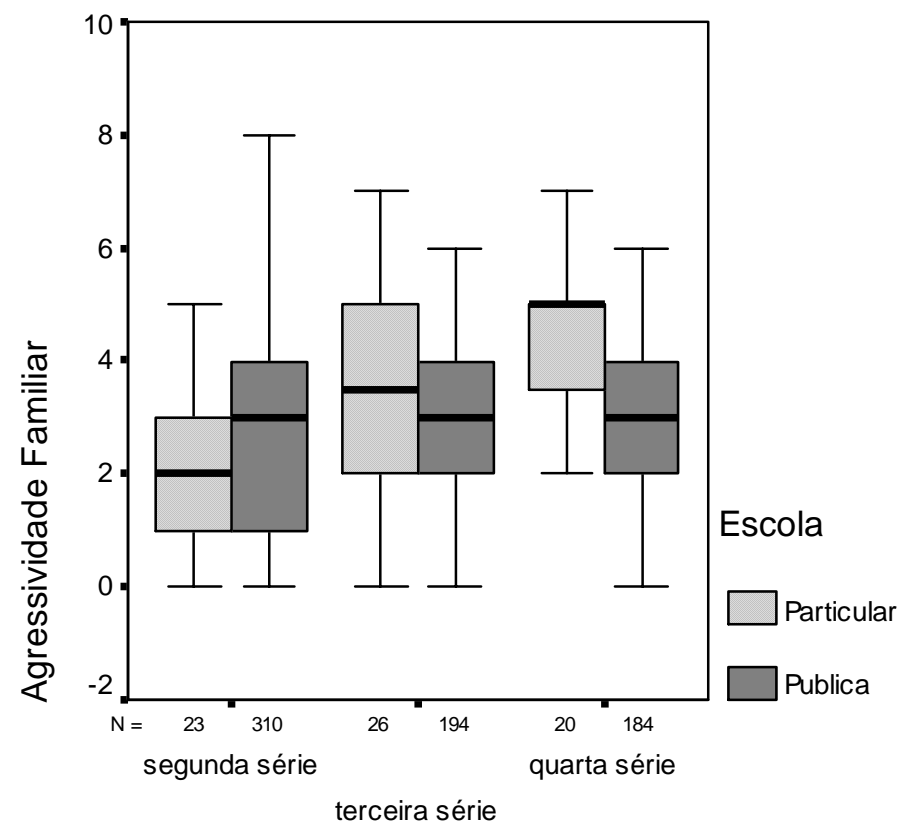

Série

Figura 1. Média da agressividade familiar por série e tipo de escola

Ao lado disso, está como são atendidas e consideradas as dificuldades dos estudantes pelos professores e pares, como destacam Papalia e Olds (2000). Pode-se inferir ainda, com base no estudo de Bierman, Smoot e Aumiller (1993) que essa postura dos profissionais da escola leva os alunos agressivos a se sentirem rejeitados, tendendo a demonstrar mais comportamentos agressivos.

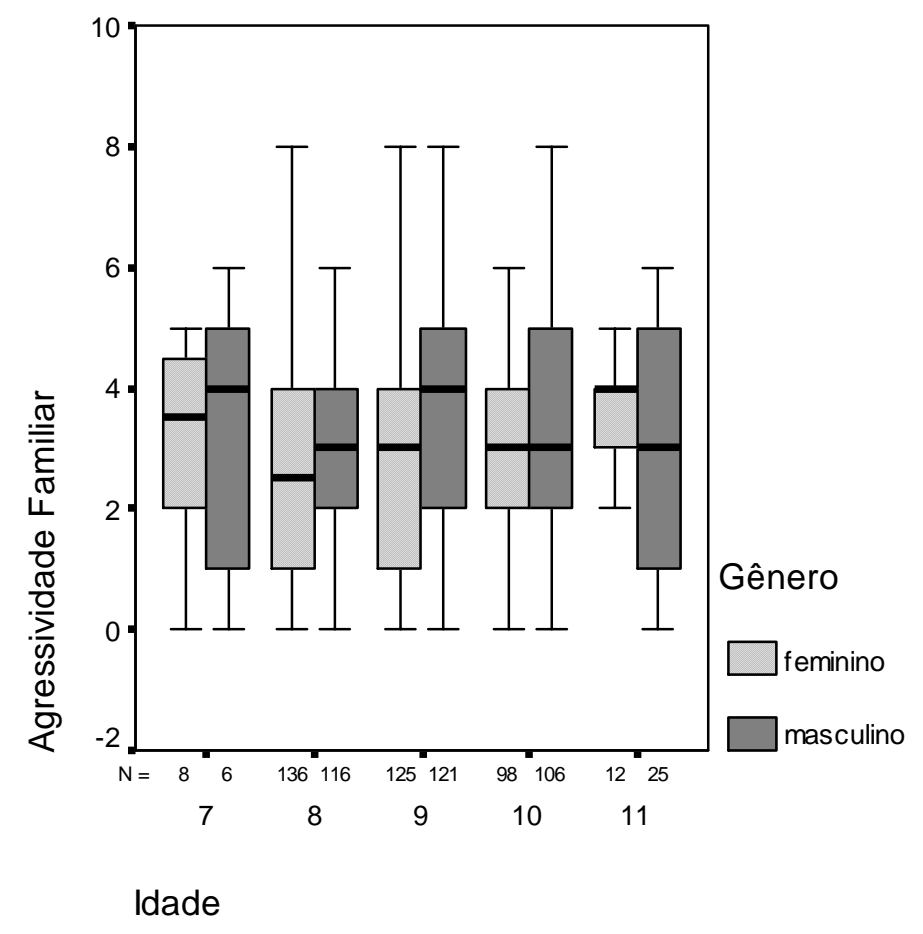

Figura 2. Média da agressividade familiar por idade e gênero 
$\mathrm{Na}$ Figura 2, observa-se que os participantes que possuem sete, nove e onze anos apresentam maiores índices de agressividade. Verifica-se um menor escore aos oito e aos dez anos, havendo menor agressividade aos 8 anos. Resultado semelhante foi encontrado no estudo de Gardner, Powell e Grantham-McGregor (1998), entre as crianças de $5^{\mathrm{a}}$ e $6^{\mathrm{a}}$ série cujo grupo de alunos mais velhos ( $M=11,4$ anos) apresentou escores mais altos de agressividade. Também se verifica que, dos sete aos dez anos de idade, a média apresentada pelas crianças do gênero feminino são menores do que as do gênero masculino, e apenas aos onze anos as meninas apresentaram uma média mais alta quando comparadas aos meninos. Porém, é relevante ressaltar que, para as idades de sete $(N=14)$ e onze anos $(N=37)$, a amostra é pequena, pois são os mais novos e mais velhos frequentando a $2^{\mathrm{a}}$ e $4^{\mathrm{a}}$ séries, respectivamente.

Tabela 1. Valores de média, desvio padrão e índices de $t$ de Student para o gênero e tipo de escola na subescala de agressividade familiar

\begin{tabular}{|c|c|c|c|c|c|c|}
\hline \multicolumn{2}{|c|}{ Agressividade Familiar } & $\mathrm{N}$ & Média & Desvio padrão & $\mathrm{t}$ & $\mathrm{p}$ \\
\hline \multirow[t]{2}{*}{ Gênero } & feminino & 382 & 2,81 & 1,88 & $-3,66$ & 0,00 \\
\hline & masculino & 376 & 3,31 & 1,90 & & \\
\hline \multirow[t]{2}{*}{ Tipo de escola } & particular & 69 & 3,38 & 1,98 & 1,47 & 0,14 \\
\hline & pública & 689 & 3,02 & 1,89 & & \\
\hline
\end{tabular}

significativo para $p<0,01 ; \alpha=0,05$

Verificou-se que os meninos apresentaram índices de agressividade mais altos e significativamente diferentes em relação às meninas (Tabela 1). Os resultados do presente estudo são semelhantes aos de Sisto e Fernandes (2004) e Leme (2004), que mostram a tendência dos meninos a apresentarem condutas mais agressivas, quando comparados com as meninas.

Cabe destacar que, segundo revisão feita por Cia, Williams e Aiello (2005), apesar do pai ter uma interação com os filhos que equivale a $25 \%$, da que tem a mãe, sua influência como modelo para os meninos e o suporte afetivo dispensado a eles são aspectos que possibilitam um desenvolvimento infantil saudável ou vulnerável. Identificaram que o maior índice de comportamentos agressivos em crianças, tanto na família quanto na escola, ocorreu quando o pai se mostrava hostil, agressivo, coercitivo e apresentava comportamentos antisociais.

Não houve diferença significativa por tipo de escola frequentada. Apesar do escore médio da escola particular ter sido maior que o da pública, não foi suficiente para diferenciar os grupos estatisticamente (Tabela 2). É importante lembrar que os participantes da escola particular equivalem a 9,1\% do total. Faz-se necessário investigar essa relação com grupos mais homogêneos, pois esse dado pode vir a indicar resiliência - superação de fatores de estresse e adversidade (Rutter, 1999) por parte dos alunos de escola pública, por um lado, e baixa resistência à frustração, falta de motivação, indícios de depressão, por outro lado, para os estudantes da escola particular (BolsoniSilva \& Marturano, 2006).

Tabela 2. Valores de média, desvio padrão e índices de ANOVA por idade e série frequentada na subescala de agressividade familiar

\begin{tabular}{|c|c|c|c|c|c|c|}
\hline \multicolumn{2}{|c|}{ Agressividade Familiar } & $\mathrm{N}$ & Média & Desvio Padrão & $\mathrm{F}$ & $\mathrm{p}$ \\
\hline \multirow[t]{5}{*}{ Idade } & 7 anos & 14 & 3,21 & 1,97 & & \\
\hline & 8 anos & 252 & 2,74 & 1,96 & 2,81 & 0,02 \\
\hline & 9 anos & 246 & 3,14 & 1,87 & & \\
\hline & 10 anos & 204 & 3,29 & 1,84 & & \\
\hline & 11 anos & 37 & 3,30 & 1,88 & & \\
\hline \multirow[t]{3}{*}{ Série } & $2^{a}$. série & 333 & 2,85 & 2,00 & & \\
\hline & $3^{a}$. série & 218 & 3,28 & 1,83 & 3,88 & 0,02 \\
\hline & $4^{\mathrm{a}}$. série & 202 & 3,16 & 1,79 & & \\
\hline
\end{tabular}

significativo para $p<0,01 ; \alpha=0,05$ 
Constataram-se diferenças significativas para idade e série quanto à agressividade familiar (Tabela 2). As diferenças entre 8 e 10 anos $(p<0,01)$ e da $2^{\mathrm{a}}$ para a $4^{\mathrm{a}}$ série $(p<0,02)$, segundo análise usando Teste de Tukey post hoc, foram significativas quanto ao escore de agressividade. Tal resultado corrobora o estudo de Leme (2004), que afirma haver uma evolução gradual dos comportamentos agressivos da criança a partir do ingresso no ensino fundamental. O período mais agressivo é por volta dos 10 anos de idade, quando frequenta a $4^{a}$ série. No estudo de Sisto e Fernandes (2004) foi observado também aumento de agressividade em razão da idade e série frequentada relacionada à dificuldade em escrita.

Agressividade na escola
Para a agressividade escolar, a média foi de 1,12 e desvio padrão de 1,50. Foi possível constatar uma concentração muito significativa, de 0 a 2, cujos percentuais foram de 49,1\% e 14,1\%, explicando $84,5 \%$ das respostas. Em contrapartida, as pontuações sete e oito apresentaram uma porcentagem de $0,8 \%$, considerada muito baixa. Pode-se perceber então, que a média obtida foi muito inferior ao ponto médio da escala (4), que podia variar de 0 a 8 pontos.

As crianças apresentaram poucas condutas agressivas quanto ao contexto escolar. Isso pode ser explicado, supondo-se que a relação com os professores é amistosa e eles se apresentam de maneira empática e afetuosa, estimulando o comportamento prestativo e zeloso da criança (Papalia \& Olds, 2000).

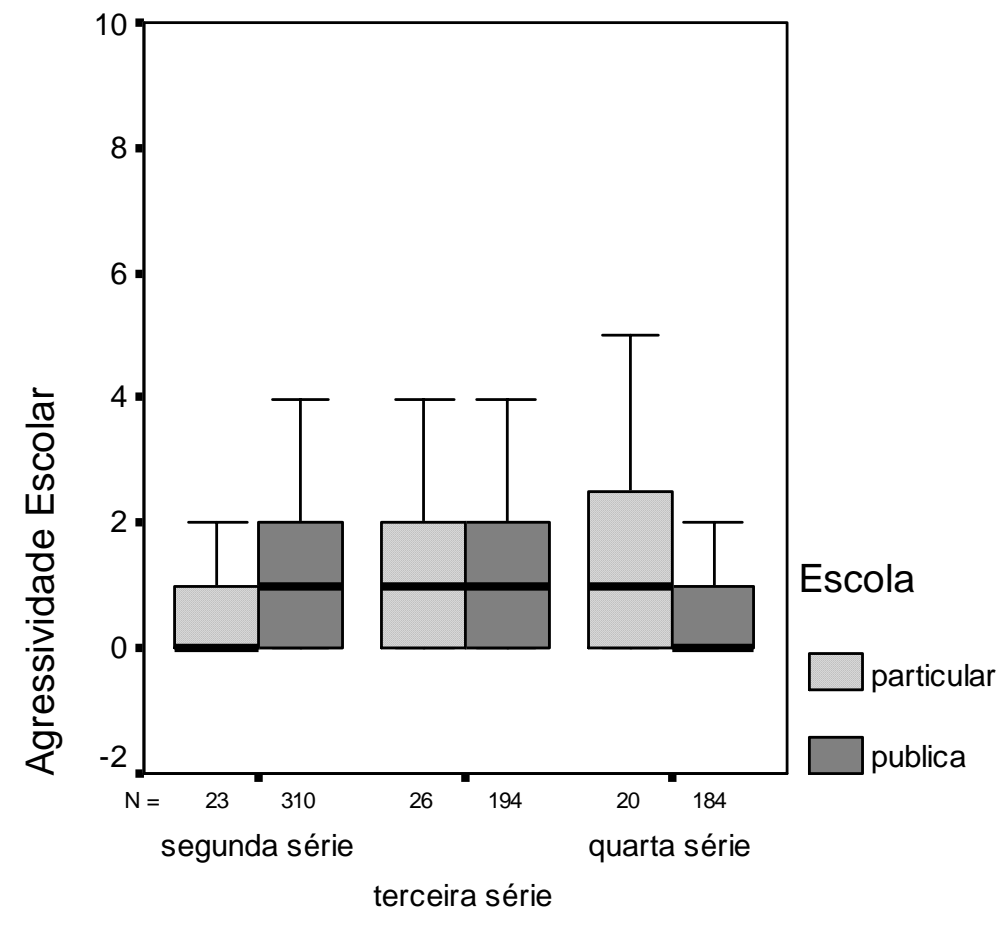

\section{Série}

Figura 3. Média da agressividade escolar por série e tipo de escola

$\mathrm{Na}$ Figura 3 pode-se observar que, para a segunda série, a escola da rede particular de ensino apresentou a menor média de expressão de comportamento agressivo. Também se destaca a terceira série, com escores médios muito próximos em ambas as escolas. A escola particular apresentou um escore médio bem superior ao da pública na quarta série. 


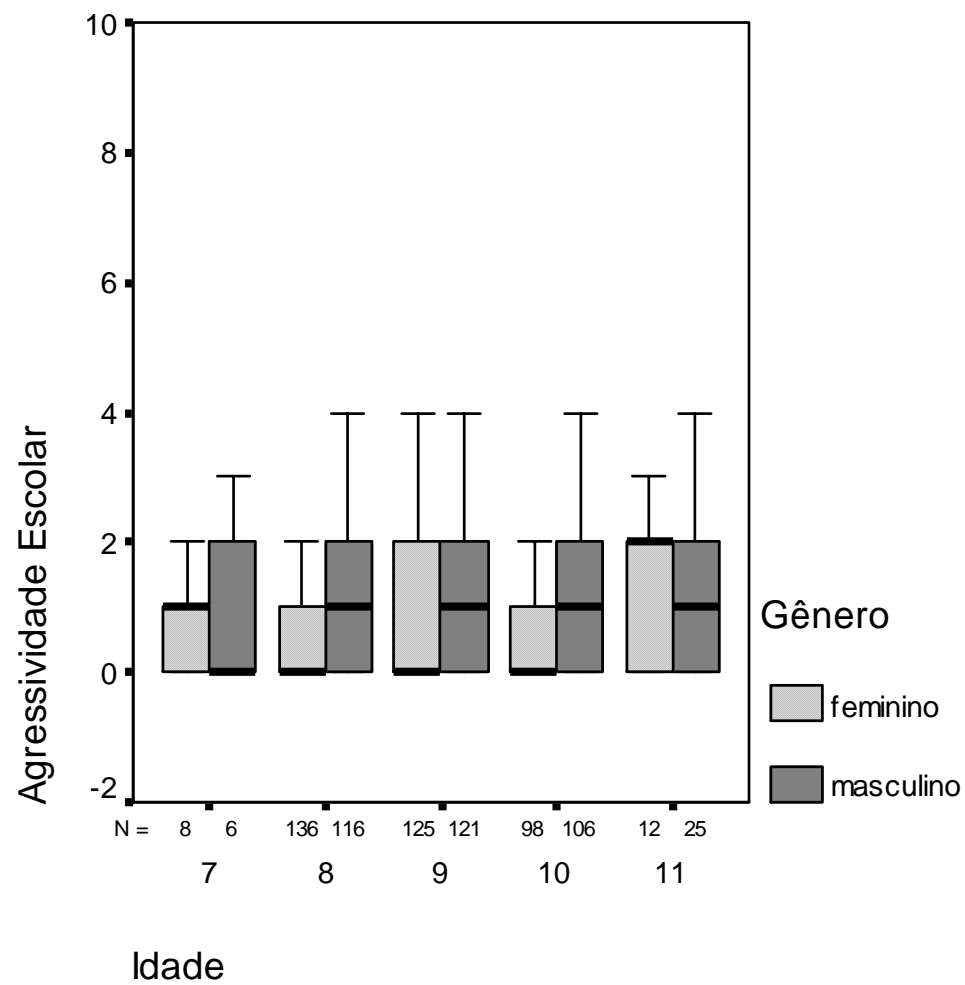

Figura 4. Média da agressividade escolar por idade e gênero

Verifica-se, na Figura 4, que a média apresentada pelas meninas foi menor que à dos meninos aos sete, oito e dez anos. Mostraram-se equivalentes aos nove e onze anos.

Tabela 3. Valores de média, desvio padrão e índices de $t$ de Student para o gênero e tipo de escola na subescala de agressividade escolar

\begin{tabular}{|c|c|c|c|c|c|c|}
\hline \multicolumn{2}{|c|}{ Agressividade escolar } & $\mathrm{N}$ & Média & Desvio padrão & $t$ & $p$ \\
\hline \multirow[t]{2}{*}{ Gênero } & feminino & 382 & 1,02 & 1,46 & $-1,78$ & 0,07 \\
\hline & masculino & 376 & 1,22 & 1,54 & & \\
\hline \multirow[t]{2}{*}{ Tipo de escola } & particular & 69 & 1,22 & 1,62 & 0,58 & 0,62 \\
\hline & pública & 689 & 1,11 & 1,49 & & \\
\hline
\end{tabular}

significativo para $p<0,01 ; \alpha=0,05$

Não se constataram diferenças significativas por gênero e tipo de escola frequentada para agressividade escolar no presente estudo (Tabela 3). A idade e série também não influenciaram os índices de agressividade escolar (Tabela 4).

Diferentemente da agressividade familiar, observou-se que na subescala escolar os participantes apresentaram menores condutas de agressividade, confirmando os resultados encontrados por Sisto e Fernandes (2004), que afirmam maiores índices de agressividade em situação familiar do que em situação escolar. Fazse necessário salientar que a escala de agressividade familiar apresenta uma maior porcentagem de crianças $(N=22,6 \%)$ que apresentaram condutas agressivas em relação ao total de participantes e às agressivas na escola $(N=4,2 \%)$.

Leme (2004) analisa que há transferência de agressividade entre contextos, sendo a generalização mais frequente de casa para a escola. Cabe destacar que se tem investigado os comportamentos agressivos de crianças mais em relação ao ambiente familiar do que ao escolar, apesar de existir já verificada uma relação entre as dificuldades de aprendizagem e problemas de comportamento, em especial a agressividade, 
enquanto um desvio de comportamento social (Bolsoni-Silva \& Marturano, 2006).

A agressividade infantil direcionada aos colegas da mesma idade e ao grupo de iguais, segundo Lisboa e Koller (2001), é diferenciada daquela dirigida aos professores e aos pais e familiares. Essa diferença certamente baseia-se na percepção da autoridade que pais e professores ocupam. Um grande número de estudos brasileiro, como analisaram Bolsoni-Silva e cols. (2006), relativos a tais aspectos no contexto escolar, referem-se à avaliação das habilidades sociais.

Tabela 4. Valores de média, desvio padrão e índices de ANOVA por idade e série frequentada na subescala de agressividade escolar

\begin{tabular}{ccccccc}
\hline \multicolumn{2}{c}{ Agressividade escolar } & $\mathrm{N}$ & Média & Desvio padrão & $F$ & $p$ \\
\hline Idade & 7 anos & 14 & 0,79 & 0,97 & & \\
& 8 anos & 252 & 1,13 & 1,60 & 0,60 & 0,66 \\
& 9 anos & 246 & 1,09 & 1,39 & & \\
\multirow{2}{*}{ Série } & 10 anos & 204 & 1,12 & 1,50 & & \\
& 11 anos & 37 & 1,43 & 1,36 & 0,32 \\
& $2^{\text {a }}$ série & 333 & 1,16 & 1.56 & & \\
\hline
\end{tabular}

significativo para $p<0,01 ; \alpha=0,05$

\section{Considerações finais}

Objetivou-se com este estudo caracterizar crianças que frequentam o ensino fundamental quanto à sua percepção acerca da agressividade na família e na escola, e verificar também as possíveis relações desta variável com gênero, faixa etária, série e tipo de escola.

Dentre os aspectos encontrados com os resultados apresentados, observou-se que a Escala de agressividade familiar apresentou escore superior às outras duas escalas de agressividade. Observaram-se diferenças significativas de agressividades entre os gêneros, já que os meninos apresentam mais comportamentos agressivos quando comparados às meninas, comprovando-se resultados de outras pesquisas (Gomide, 2000; Leme, 2004; Sisto \& Fernandes, 2004). Houve diferenças significativas entre as Escalas de Agressividade Familiar e Geral para os gêneros, para a Escala Familiar entre as séries. Percebe-se a necessidade de pesquisas futuras para a verificação dos resultados apresentados, com relação aos tipos de escolas, já que neste estudo a amostra da escola particular foi significativamente inferior à da escola pública.

Outras variáveis como ambiente familiar, relacionamento entre pais e filhos, entre outros, podem ser investigadas futuramente. Isto, por estarem relacionadas ao contexto familiar, o qual revelou, no presente estudo, maior índice médio de comportamentos agressivos.

\section{Referências}

Bandura, A. (1973). Aggression, a social learning analysis. Englewood Cliffs: Prentice Hall.

Bazi, G. A. do P. (2003). As dificuldades de aprendizagem na escrita e suas relações com traços de personalidade e emoções. Qualificação de Doutorado. São Paulo: Universidade Estadual de Campinas.

Bee, H. (1997). O ciclo vital. Porto Alegre: Artmed.

Bolsoni-Silva, A. J. \& Marturano, E. M. (2006). A qualidade da interação pais e filhos e sua relação com problemas de comportamentos de pré-escolares. Em M. Bandeira, Z. A. Del Prette \& A. Del Prette (Orgs.), Estudos sobre habilidades sociais e relacionamento interpessoal (pp. 69-83). São Paulo: Casa do Psicólogo.

Bolsoni-Silva, A. J., Del Prette, Z. A. P., Del Prette, G., Montanher, A. R. P., Bandeira, M. \& Del Prette, A. (2006). A área das habilidades sociais no Brasil: uma análise dos estudos publicados em periódicos. Em M. Bandeira, Z. A. Del Prette \& A. Del Prette (Orgs.), Estudos sobre habilidades sociais $e$ relacionamento interpessoal (pp. 17-46). São Paulo: Casa do Psicólogo.

Bronfernbrenner, U. (1996). A ecologia do desenvolvimento bumano: experimentos naturais $e$ planejados. Porto Alegre: Artes Médicas.

Buss, A. H. (1961). The psychological of aggression. Nova Iorque: Wiley. 
Chaves, S. L. E., Kelder, S. \& Orpinas, P. (2002). La relación entre juegos de videos violentos, la aculturación y la agresión entre adolescentes latinos. Biomédica, 22, 398-406.

Cia, F., Williams, L. C. A. \& Aielo, A. L. R. (2005). Influências paternas no desenvolvimento infantil: revisão da literatura. Psicologia Escolar Educacional, 9(2), 225-233.

Davidoff, L. L. (2001). Introdução à psicologia. $3^{\mathrm{a}} \mathrm{ed}$. São Paulo: Makron Books.

Garcia, N. J. \& Yunes, M. A. M. (2006). Resiliencia e monoparentalidade. Em D. D. Dell Aglio, S. H. Koller \& M. A. M. Yunes (Orgs.). Resiliencia e psicología positiva: interfaces do risco à proteção (pp. 117-172). São Paulo: Casa do Psicólogo.

Gardner, J. M. M., Powell, C. A. \& GranthamMcGregor, S. M. (1998). A case-control study of agressive and pro-social Jamaican school boys. Scientific Metting, 43, 22-25.

Gomide, P. I. C. (2000). A influência de filmes violentos em comportamento agressivo de crianças e adolescentes. Psicologia: Reflexão $e$ Crítica, 13, 147-141.

Leme, M. I. S. (2004). Resolução de conflitos interpessoais: interações entre cognição e afetividade na cultura. Psicologia: Reflexão $e$ Crítica, 17(3) 367-380.

Lisboa, C. S. M. \& Koller, S. H. (2001). Construção da validação de conteúdo de uma escala de percepção, por professores, dos comportamentos agressivos de crianças na escola. Psicologia em estudo, 6, 59-69.
Loreto, M., Milan, E., Ramos, L., Parra, J. \& Elguezábal, B. (1998). Efecto de lãs técnicas del superaprendizaje em las reacciones agresivas infantiles: que se manifestan em el ambiente escolar. Niños, 31, 101-130.

Papalia, D. E. \& Olds, S. W. (2000). Desenvolvimento bumano. ( $7^{\mathrm{a}}$ ed.) Porto Algre: Artmed.

Polônia, A. da C., \& Dessen, M. A. (2005). Em busca de uma compreensão das relações entre família e escola. Psicologia Escolar e Educacional, 9, 303-312.

Rutter, M. (1999). Resilience concepts and findings: implications for family therapy. Journal of Family Therapy, 21, 119-144.

Sisto, F. F. \& Fernandes, D. C. (2004). Dificuldades linguísticas na aquisição da escrita e agressividade. Psicologia Escolar e Educacional, 8, 75-84.

Sisto, F. F. \& Bazi, G. A. P. (1998). Escala de Agressividade para crianças e jovens. Faculdade de Educação. Campinas: Universidade Estadual de Campinas.

Skinner, B. F. (1974). Sobre o behaviorismo. São Paulo: Cultriz.

Wagner, T. M. C. \& Biaggio, A. M. B. (1996). Relações entre o comportamento agressivo dos pré-escolares e a expressão da raiva de seus pais. Estudos de Psicologia, 13, 59-68.

Recebido em março de 2008 Reformulado em setembro de 2008 Aprovado em novembro de 2008

Sobre as autoras:

Maria Cristina Rodrigues Azevedo Joly é doutora em Psicologia pela Universidade de São Paulo. Atua como docente na graduação e pós-graduação em Psicologia da Universidade São Francisco.

Anelise da Silva Dias é graduada em Psicologia com mestrado em Avaliação Psicológica Educacional pela Universidade São Francisco e atualmente doutoranda com bolsa CAPES.

Janete Aparecida da Silva Marini é graduada em Pedagogia com mestrado em Avaliação Psicológica Educacional pela Universidade São Francisco e doutoranda em Educação pela Unicamp. Atua como docente em curso de graduação na universidade Unianchieta e como diretora de escola de educação básica na prefeitura do município de Jundiaí. 
